\title{
Mortality of site-specific cancer in patients with schizophrenia: a systematic review and meta-analysis
}

\author{
Liwei $\mathrm{Ni}^{\dagger}$, Jian $\mathrm{Wu}^{\dagger}$, Yuming Long, Jialong Tao, Jianhao Xu, Xuya Yuan, Na Yu, Runhong Wu and Yusong Zhang
}

\begin{abstract}
Background: Numerous studies have reported contradicting results on the relationship between cancer mortality and schizophrenia. Our aim is to quantify the mortality rate of common site-specific cancers among patients with schizophrenia and to synthesize the available research evidence.

Methods: We performed a systemic search of the PubMed, EMBASE and Web of Science databases. Studies reporting the mortality rate of different cancer in patients with schizophrenia were included. A random-effects model was applied to calculate the pooled relative risks (RRs) with 95\% confidence intervals (95\%Cls).

Results: Seven studies consisting of 1,162,971 participants with schizophrenia were included in this meta-analysis. Data regarding mortality risk of breast, colon, lung and prostate cancer among schizophrenia patients were subjected to quantitative analysis. Pooled results showed significant increases in mortality risk of breast cancer $(\mathrm{RR}=1.97,95 \% \mathrm{Cl}$ 1.38-2.83), lung cancer ( $R R=1.93,95 \% \mathrm{Cl} 1.46-2.54)$ and colon cancer $(\mathrm{RR}=1.69,95 \% \mathrm{Cl} 1.60-1.80$ ) in patients with schizophrenia compared with those in the general population or control group. The mortality risk of prostate cancer increased in male patients, although no significant difference was detected ( $\mathrm{RR}=1.58,95 \% \mathrm{Cl}$ 0.79-3.15). Increased risks of mortality from lung and colon cancer were observed in female patients $(R R=2.49,95 \% \mathrm{Cl} 2.40-2.59$ and $R R=2.42$, $95 \% \mathrm{Cl} 1.39-4.22$, respectively) and elevated risks of mortality from lung and colon cancer in male patients ( $\mathrm{RR}=2.40$, $95 \% \mathrm{Cl} 2.30-2.50$ and $\mathrm{RR}=1.90,95 \% \mathrm{Cl} 1.71-2.11$, respectively) were detected.
\end{abstract}

Conclusions: Individuals with schizophrenia have a significantly high risk of mortality from breast, colon, and lung cancer.

Keywords: Schizophrenia, Cancer, Mortality, Meta-analysis

\section{Background}

Schizophrenia is often described as one of the most severe mental disorders. The worldwide prevalence of schizophrenia is approximately $1 \%$ [1]. Individuals with schizophrenia have an extraordinarily short life expectancy and die approximately $10-20$ years younger than the general population due to the high mortality, mostly resulting from poor medical care, unhealthy lifestyle factors, the side effects of antipsychotic medicine, and suicide [2-4]. The mortality presented by most cancers contributes to the reduced life expectancy of patients with mental illness [5].

\footnotetext{
* Correspondence: zhangyusong19@163.com

${ }^{\dagger}$ Liwei Ni and Jian Wu contributed equally to this work.

Department of Oncology, The Second Affiliated Hospital of Soochow

University, Suzhou, Jiangsu 215004, People's Republic of China
}

As early as the 1990s, individuals with schizophrenia were reported to have a lower or similar risk of cancer mortality $[6,7]$, a finding that was supported by Giovanni Perini et al. [8]. However, there are a good many studies that demonstrated an increased cancer-related mortality in people with schizophrenia [9-11]. A metaanalysis by Zhou et al. found a high risk of overall cancer mortality after a diagnosis of schizophrenia, but there was highly significant and inexplicable heterogeneity among studies [12].

With respect to specific cancer sites, the results were inconsistent. Tran et al. observed an increased mortality rate from breast and lung cancer in schizophrenia patients [9], whereas Perini et al. described an elevated mortality risk of breast and lung cancer among patients

(c) The Author(s). 2019 Open Access This article is distributed under the terms of the Creative Commons Attribution 4.0 International License (http://creativecommons.org/licenses/by/4.0/), which permits unrestricted use, distribution, and reproduction in any medium, provided you give appropriate credit to the original author(s) and the source, provide a link to the Creative Commons license, and indicate if changes were made. The Creative Commons Public Domain Dedication waiver (http://creativecommons.org/publicdomain/zero/1.0/) applies to the data made available in this article, unless otherwise stated. 
with schizophrenia [8]. These conflicting findings have sparked controversial debates on the association between schizophrenia and the mortality risk of site-specific cancers. Therefore, the present meta-analysis aims to systematically review the available evidence regarding the mortality risk of site-specific cancers in patients with schizophrenia and quantify mortality risk differences by cancer type.

\section{Methods}

\section{Search strategy}

This meta-analysis and systematic review were conducted in accordance with the Meta-analysis of Observational Studies in Epidemiology [13] and the Cochrane Handbook for Systematic Reviews of Interventions guidelines [14]. We systematically searched the PubMed, EMBASE and Web of Science databases for observational studies using the following MeSH terms and textwords: "schizophrenia" [Mesh], "schizophreni"," "carcinoma" [Mesh], "carcinoma"," "malignant tumor," "cancer," "malignant neoplasm, " "mortality" [Mesh], "mortality"," "death rate," and "case fatality rate." The search was confined to studies on humans published in English up to October 20, 2018. Relevant articles in the reference lists and grey literature were manually screened to update our first literature search.

\section{Inclusion/exclusion criteria}

EndNote X8 software was used to screen relevant articles meeting the criteria for admission and exclude incompatible articles. Studies eligible for inclusion in this meta-analysis must fulfill the following criteria: (1) can be searched for a full text document in English; (2) designed as a retrospective or prospective cohort or follow-up study; (3) the study population already had schizophrenia as a baseline with no history of cancer; (4) the general population or the participants without a diagnosis of schizophrenia formed the control group; and (5) mortality rate [reported as relative risks (RRs) or standard mortality ratios (SMRs) or hazard ratios (HRs) with $95 \%$ confidence intervals (95\%CIs)] of some sitespecific cancers in patients with schizophrenia were documented or could be calculated using data derived from the corresponding article. Studies were excluded if they (1) reported cancer mortality rates without clarification by tumor location and (2) were letters, editorials, abstracts, reviews, case reports, or case-control studies. Two authors (Liwei Ni and Yuming Long) selected the eligible studies independently according to the flow diagram cited from the Preferred Reporting Items for Systematic Reviews and Meta-Analyses (PRISMA) [15] and came to a consensus after cross-checking. Cohen's kappa statistic was used to measure inter-rater reliability (SPSS version 24. 0, SPSS Inc., Chicago, IL, USA).

\section{Data extraction}

Data were extracted from each study by two authors (Liwei $\mathrm{Ni}$ and Yuming Long) independently, and the following variables were obtained: the last name of the first author, publication year, country in which the study was conducted, study design, size of the study population, follow-up period, types of cancer, number of site-specific cancer cases, methods used for confirmation of schizophrenia and cancer death, and mortality risk of sitespecific cancers evaluated with 95\%CIs. We extracted RRs or SMRs or HRs reflecting the maximum degree of control over potential confounders for preliminary analysis. When necessary, we contacted the primary authors for additional information.

\section{Quality assessment}

The quality of included studies was assessed by the Newcastle-Ottawa Quality Assessment Scale (NOS, scores of $0-9$ stars), and studies with $N O S \geq 6$ were regarded as high-quality [16]. Two review authors evaluated the risk of bias for each study independently and finally reached a consensus.

\section{Statistical analysis}

All data analyses were performed using the Stata (Version 14.0, StataCorp LP). SMR or HR data were extracted and was transformed into RRs on account of the absolutely low risk of site-specific cancer in patients with schizophrenia, thereby providing a rational basis to ignore differences in measures of mortality rate [17]. RRs with the corresponding 95\% CIs for each study were calculated to obtain the pooled estimates. Occasionally, $95 \%$ CI data were unavailable and calculated by $P$ value and RR [18]. RRs with 95\%CIs were calculated in a 2-by-2 contingency table [19] using data derived from the corresponding article.

The chi-squared $\left(\chi^{2}\right)$ tests provided a test of significance for heterogeneity of included studies with $P<$ 0.05. The I-squared $\left(\mathrm{I}^{2}\right)$ statistic served as an important means of quantifying the heterogeneity, which could be classified as low, moderate, and high, with upper limits of 25,50 , and $75 \%$ for $\mathrm{I}^{2}$, respectively [20]. If $\mathrm{I}^{2}>50 \%$ or $\mathrm{P}<0.05$, a significant degree of heterogeneity exists among studies. If heterogeneity existed between studies, the random-effects model was applied for meta-analysis of the RR data [20]. Moreover, we adopted a trim-and-fill method for sensitivity analysis to detect the source of heterogeneity. According to the Cochrane handbook, at least 10 studies are required to explore the presence of publication bias by constructing a funnel plot [14]. Thus, publication bias was examined by using Egger's test [21]. 


\section{Results}

Literature search

A flow diagram of the literature selection process is shown in Fig. 1. Initially, 706 articles were identified by searching three databases and manually screening the references and grey literature. Then, 179 articles were found to be duplicates and deleted. After reviewing the unique titles and abstracts, 74 records appeared to be potentially relevant for inclusion in the meta-analysis. After further full-text review, 67 studies were excluded because 15 of them did not report schizophrenia patients as the study population, and 52 lacked of data on the mortality rate of any site-specific cancer. Ultimately, seven studies were included in our meta-analysis. The kappa statistic indicated satisfactory agreement between two raters $(\mathrm{kappa}=0.82)$.

\section{Study characteristics and quality assessment}

The characteristics of the included studies are depicted in Table 1. A total of 1,162,971 patients with schizophrenia were enrolled in the seven included studies. Four common cancer types (i.e., breast, colon, lung and prostate cancer) were investigated, considering that a minimum of three data values of mortality rate of a certain cancer were needed for our analysis. Most studies compared cancer mortality in the general population as a control to calculate the RRs [7-
$10,22,23]$, one study used the cancer mortality rates in a population without schizophrenia to determine RRs [24]. The mortality risk of four selected sitespecific cancers was individually reported as SMRs with 95\%CIs in major studies and documented as HRs with 95\%CIs in only one article [24]. One study did not provide data of $95 \%$ CIs corresponding to the SMRs of different cancers [9]. One study reported the data of $P$ values and RRs [23]. Thus, we calculated the value of corresponding $95 \%$ CIs.

Four of the studies provided mortaliry rates of sitespecific cancers according to gender [7, 8, 22, 24]. One article reported only on breast cancer mortality in female schizophrenic patients and lung cancer mortality in all participants with schizophrenia [9], one study merely reported mortality data for lung cancer [23], and one study did not provide the mortality data for prostate cancer [10]. The follow-up periods ranged from 7 years to 38 years. Four studies were conducted in European countries [8, 9, 22, 24], two in North America [10, 23], and one in Japan [7]. Most studies used the ICD-9 or ICD-10 and hospital records to assess schizophrenia. Confirmation of cancer death was mainly based on death registry data or death certificate.

All seven cohort studies scored no less than six stars according to the NOS scale, indicating a high level of methodological quality in this meta-analysis (Table 2).

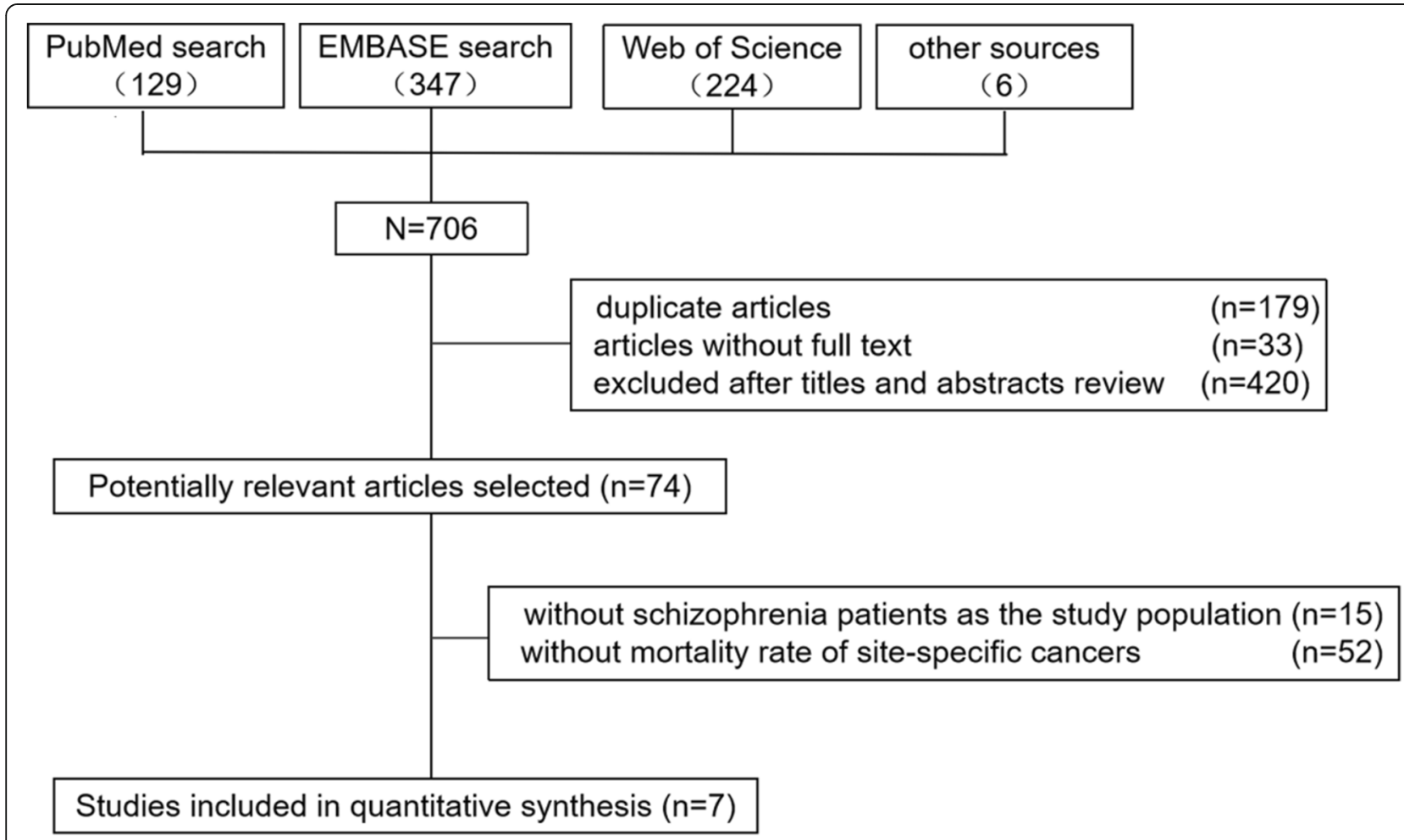

Fig. 1 The literature search processes and results 


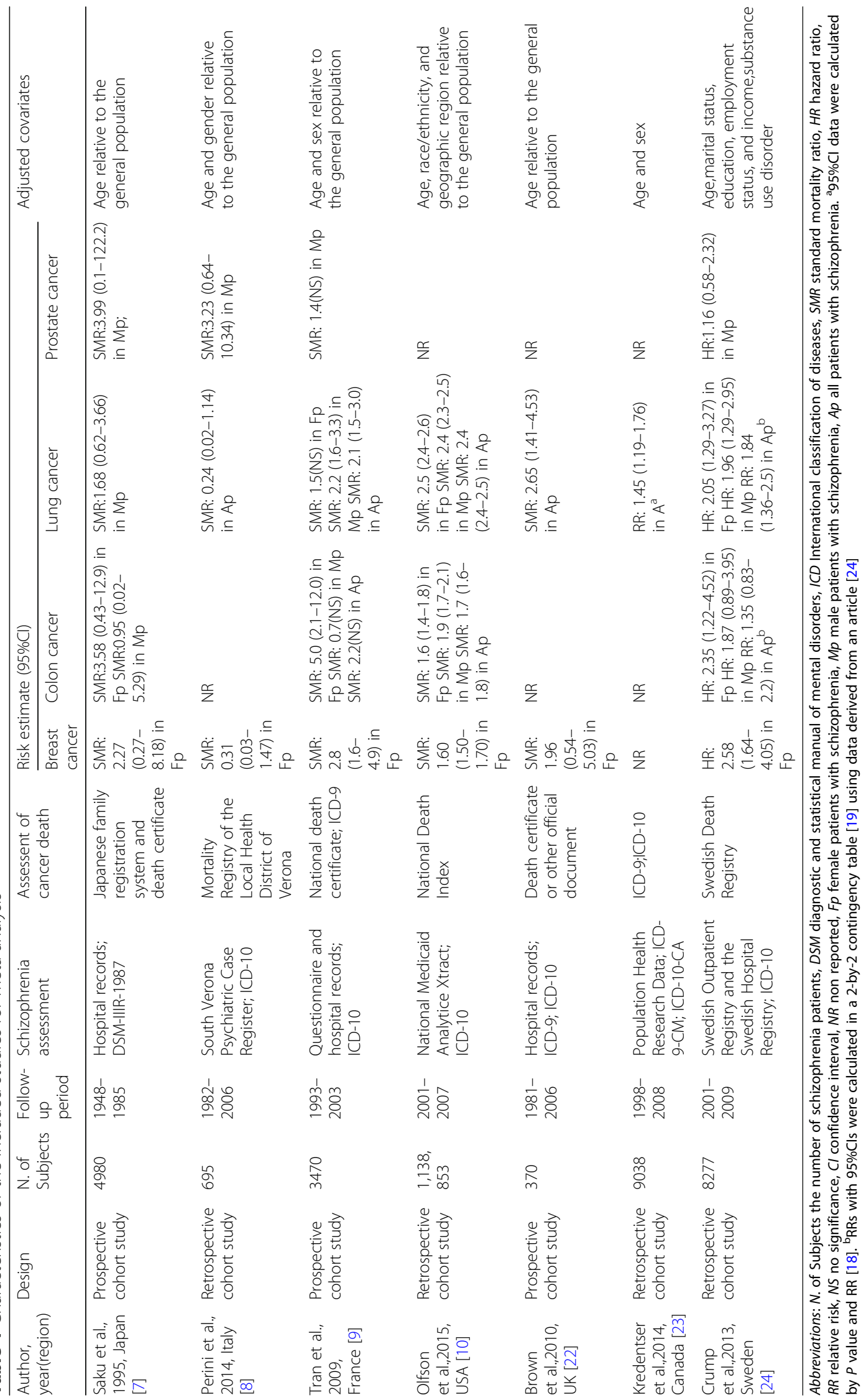


Table 2 Quality assessment of eligible studies with Newcastle-Ottawa Scale

\begin{tabular}{|c|c|c|c|c|c|c|c|c|c|}
\hline $\begin{array}{l}\text { First author, } \\
\text { year }\end{array}$ & $\begin{array}{l}\text { Representativeness } \\
\text { of exposed cohort }\end{array}$ & $\begin{array}{l}\text { Selection of } \\
\text { unexposed } \\
\text { cohort }\end{array}$ & $\begin{array}{l}\text { Ascertainment } \\
\text { of exposure }\end{array}$ & $\begin{array}{l}\text { Outcome of } \\
\text { interest not } \\
\text { present at start } \\
\text { of study }\end{array}$ & $\begin{array}{l}\text { Comparability } \\
\text { based on the } \\
\text { design or } \\
\text { analysis }\end{array}$ & $\begin{array}{l}\text { Ascertainment } \\
\text { of outcome }\end{array}$ & $\begin{array}{l}\text { Follow-up long } \\
\text { enough for } \\
\text { outcomes } \\
\text { to occur }\end{array}$ & $\begin{array}{l}\text { Adequacy } \\
\text { of followup }\end{array}$ & $\begin{array}{l}\text { Total } \\
\text { quality } \\
\text { scores }\end{array}$ \\
\hline $\begin{array}{l}\text { Saku, } \\
1995 \text { [7] }\end{array}$ & * & - & * & * & * & * & * & - & 6 \\
\hline $\begin{array}{l}\text { Perini, } \\
2014 \text { [8] }\end{array}$ & * & - & * & * & * & * & * & - & 6 \\
\hline $\begin{array}{l}\text { Tran, } \\
2009 \text { [9] }\end{array}$ & * & - & * & * & * & * & * & - & 6 \\
\hline $\begin{array}{l}\text { Olfson, } \\
2015 \text { [10] }\end{array}$ & * & - & $*$ & * & * & $*$ & * & * & 7 \\
\hline $\begin{array}{l}\text { Brown, } \\
2010[22]\end{array}$ & * & - & * & * & * & $*$ & * & - & 6 \\
\hline $\begin{array}{l}\text { Kredentser, } \\
2014 \text { [23] }\end{array}$ & * & - & * & * & * & * & * & - & 6 \\
\hline $\begin{array}{l}\text { Crump, } \\
2013 \text { [24] }\end{array}$ & * & * & * & * & * & * & * & - & 7 \\
\hline
\end{tabular}

Asterisk represents a point

\section{Mortality risk of site-specific cancer in schizophrenia}

Based on each included study's cancer classifications, we calculated the pooled RRs of four common types of cancer, including prostate (men), breast (women), lung (all patients, men, women), and colon (women, men). The mortality risk of lung and colon cancer was reported in men or women with schizophrenia. We applied the random-effects model to calculate the pooled RRs of site-specific cancers due to the presence of substantial heterogeneity among the included studies (Fig. 2). The pooled RR for breast cancer was 1.97 (95\%CI 1.38-2.83, $P<0.001)$, that for lung cancer was 1.93 (95\%CI $1.46-$

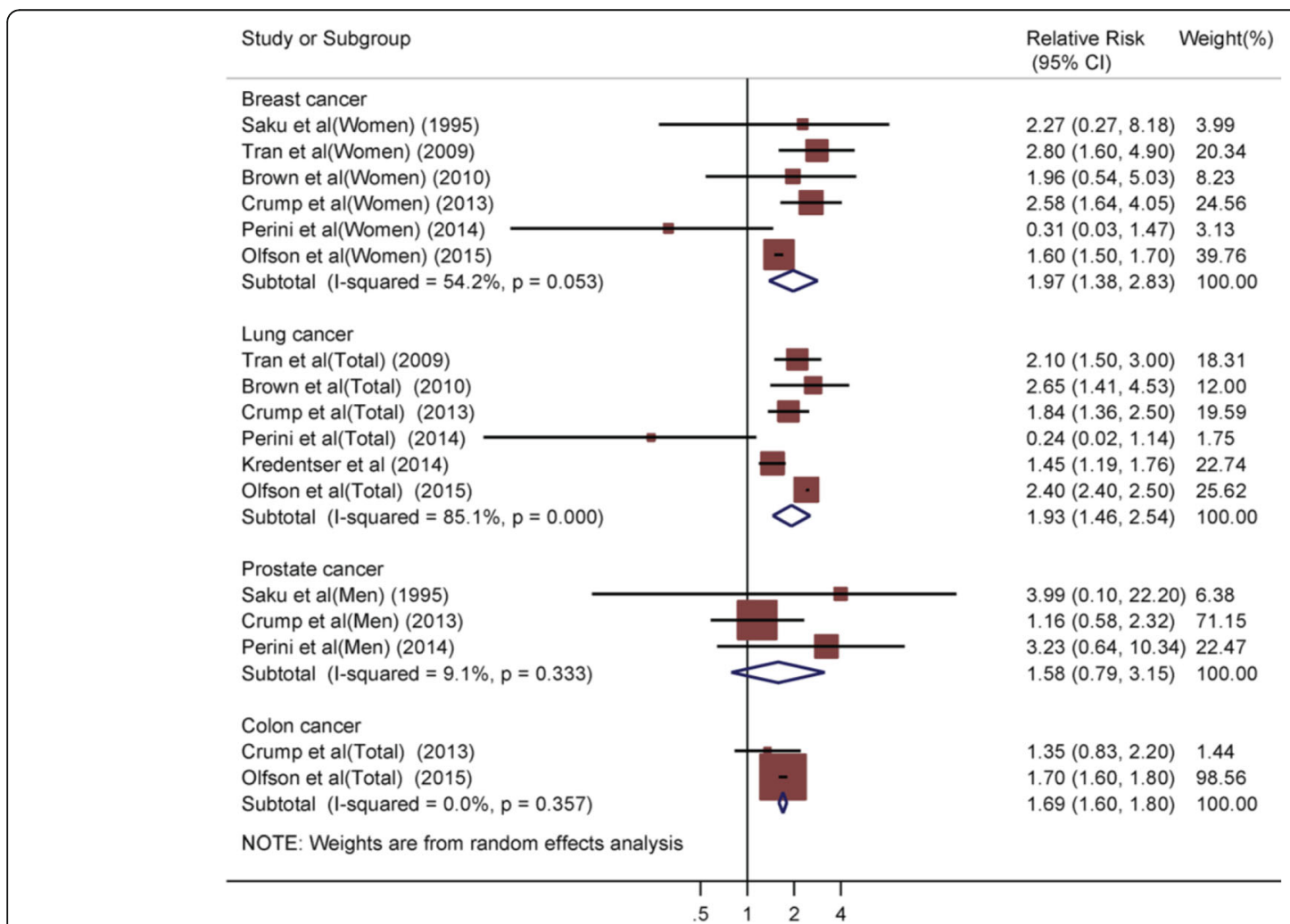

Fig. 2 Forest plot of pooled mortality rates of breast cancer, lung cancer, prostate cancer and colon cancer in patients with schizophrenia. Analysis results showed the association between schizophrenia and increased mortality risk of site-specific cancers 


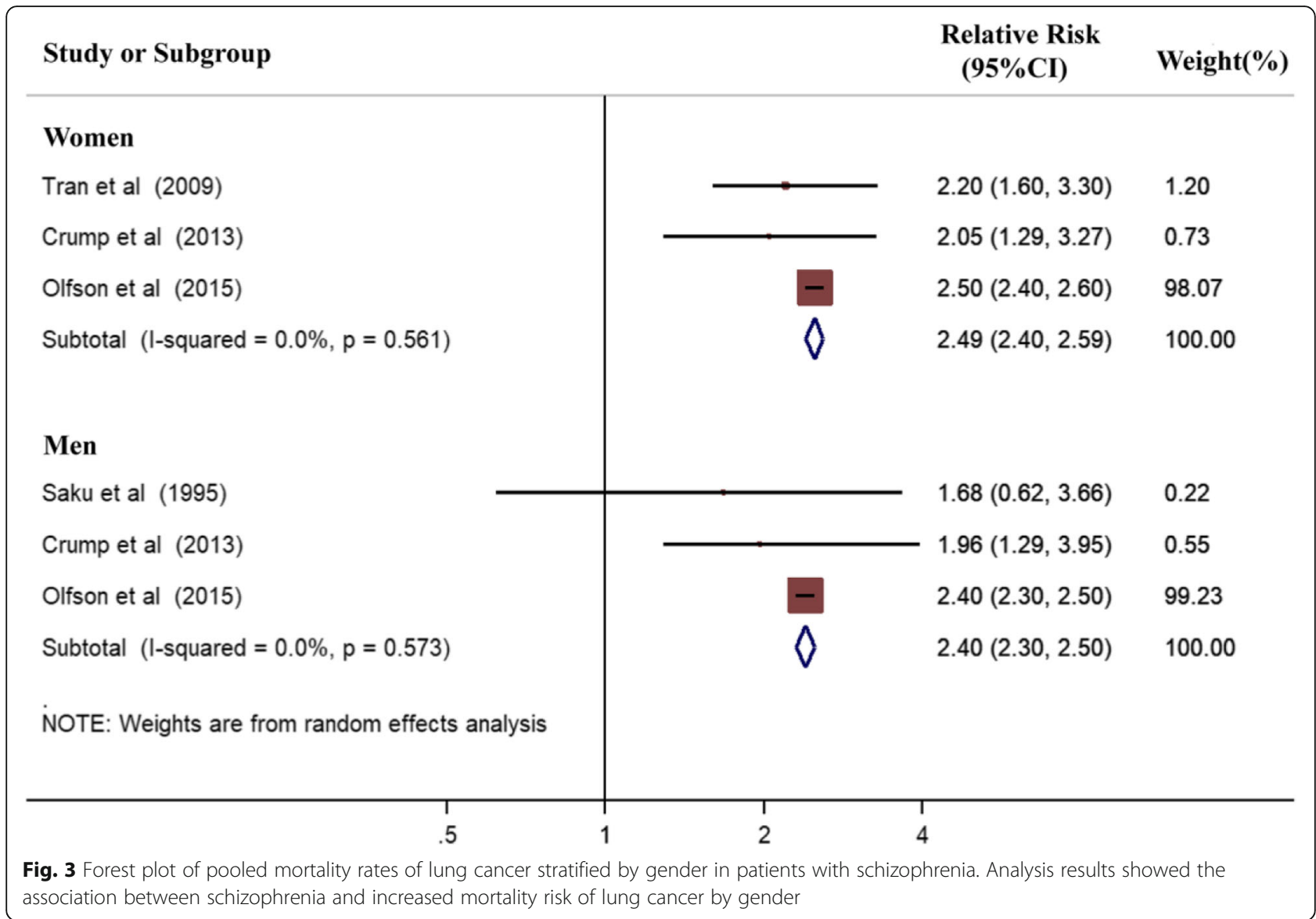

$2.54, \mathrm{P}<0.001)$, that for prostate cancer was $1.58(95 \% \mathrm{CI}$ $0.79-3.15, P=0.195)$, and that for colon cancer was 1.69 (95\%CI 1.60-1.80, $P<0.001)$. Thus, patients with schizophrenia showed significantly increased mortality risk rates of breast, lung, and colon cancer, but not prostate cancer, compared with the general population or control group.

\section{Site-specific cancer mortality analyzed according to gender}

Substantial heterogeneity was observed among the mortality rates of lung cancer in all participants with schizophrenia $\left(\mathrm{I}^{2}>50 \%\right)$. We therefore reassessed the results according to gender, which is regarded as a potential confounder (Fig. 3). We also calculated the mortality rate of colon cancer by gender (Fig. 4). For women, the pooled RRs of lung and colon cancer were 2.49 (95\% CI 2.40-2.59, $P<0.001$, Fig. 3) and 2.42 (95\%CI 1.39-4.22, $P=0.002$, Fig. 4), respectively. For men, the pooled RRs of lung and colon cancer were 2.40 (95\%CI 2.30-2.50, $\mathrm{P}<0.001$, Fig. 3) and 1.90 (95\%CI 1.71-2.11, $\mathrm{P}<0.001$, Fig. 4), respectively. Thus, the mortality rate of lung and colon cancer significantly increased in patients with schizophrenia compared with that of the general population or control group regardless of gender.

\section{Heterogeneity and sensitivity analysis}

The $X^{2}$ test and I-squared statistics were used to evaluate the heterogeneity among studies. The calculated $X^{2}$ revealed no significant heterogeneity in the mortality rates of site-specific cancer among the included studies $(P>0.05$, Figs. 2, 3, 4), except for lung cancer in all patients $(\mathrm{P}<0.001$, Fig 2$)$ and colon cancer in female patients $\left(P=0.039\right.$, Fig. 4). The $\mathrm{I}^{2}$ statistic indicated high levels of heterogeneity among the cohort studies for breast cancer $\left(\mathrm{I}^{2}=54.2 \%\right.$, Fig. 2) and lung cancer $\left(\mathrm{I}^{2}=85.1 \%\right.$, Fig. 2), as well as low levels of heterogeneity for prostate cancer $\left(\mathrm{I}^{2}=9.1 \%\right.$, Fig. 2). During analysis of cancer mortality rates by gender, significant heterogeneity was observed among the included studies for colon cancer in women $\left(\mathrm{I}^{2}=64.0 \%\right.$, Fig. 4). And statistical heterogeneity did not exist among the studies for colon cancer in men $\left(\mathrm{I}^{2}=0.0 \%\right.$, Fig. 4$)$, and lung cancer in women and men $\left(\mathrm{I}^{2}=0.0 \%\right.$, Fig. 3$)$.

Sensitivity analysis was performed to evaluate the stability of our pooled results in the random-effects model. During multivariate analysis of breast cancer mortality, the results did not significantly flip with a new RR (1.74, 95\%CI: 1.24-2.44), which was calculated by the trimand-fill method (Additional file 1: Figure S1). Each study 


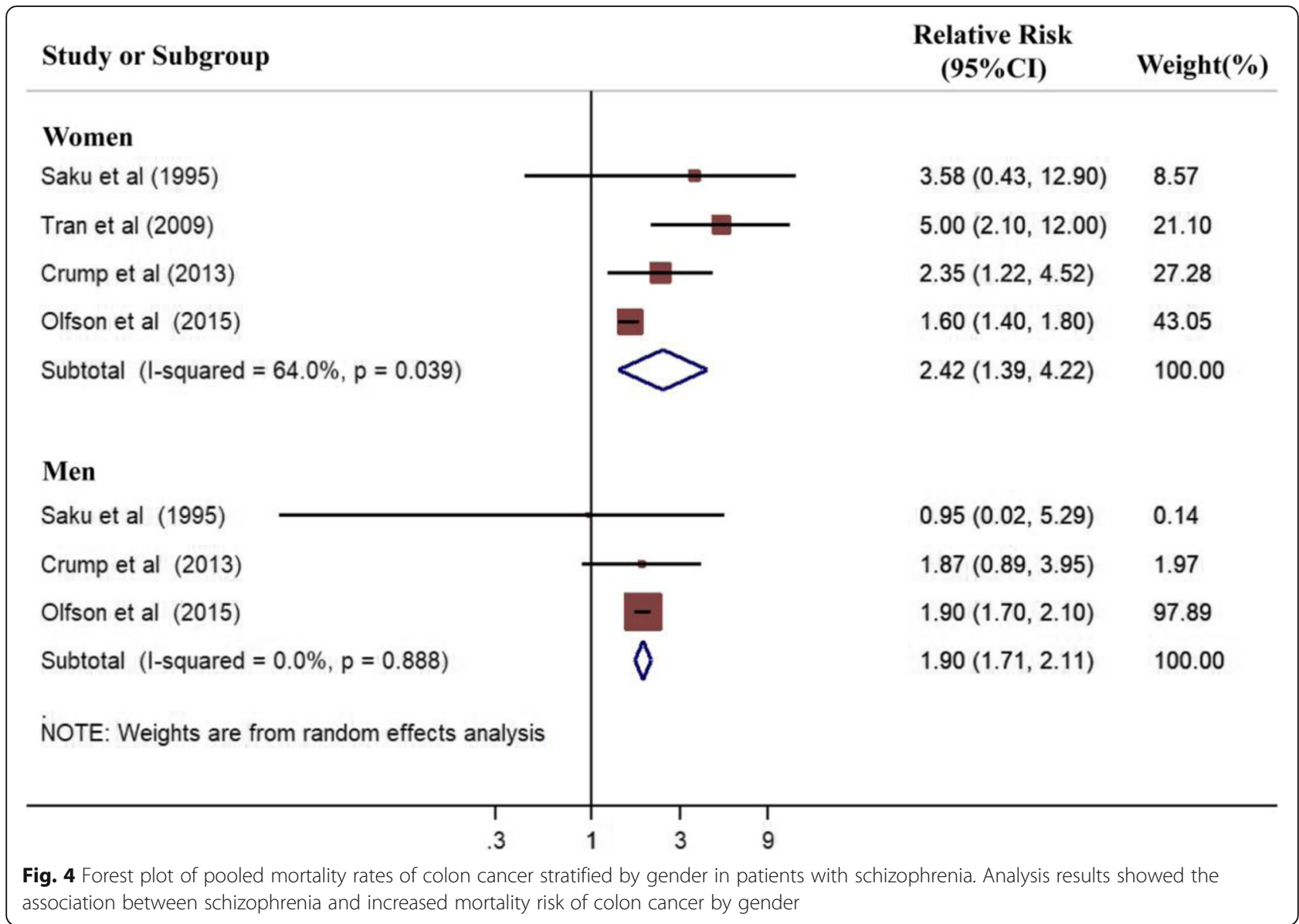

included in the meta-analysis of breast cancer made no difference to our pooled results in the random-effects model (Additional file 1: Figure S2). During multivariate analysis of lung cancer mortality, the trim-and-fill method was used to obtain a new RR $(1.93,95 \%$ CI: $1.46-2.54)$, which was roughly equivalent to the previous RR (1.97, 95\%CI: 1.38-2.83) (Additional file 1: Figure S1). Moreover, the pooled results remained stable regardless of which study in the meta-analysis of lung cancer was omitted (Additional file 1: Figure S2). During multivariate analysis of prostate cancer mortality, although the recalculated RR was similar to the previous value, with no significant difference (Additional file 1: Figure S1), the pooled result became unstable when the study by Crump et al. was excluded (Additional file 1 : Figure S2).

\section{Publication bias}

According to the Cochrane handbook, at least 10 studies are required to perform the tests for funnel plot asymmetry efficaciously. Thus, Egger's test was used to assess the potential publication bias. No evidence of potential publication bias was found among the included studies for breast cancer $(P=0.472)$, lung cancer $(P=0.120)$, and prostate cancer $(P=0.299)$. There were not enough studies for colon cancer to conduct the Egger's test.

\section{Discussion}

Main findings and comparison with other studies

The main finding of our study was that patients with schizophrenia have a higher risk of mortality from common site-specific cancers was validated, particularly by a significantly high risk of mortality from breast, lung, and colon cancer. However, the pooled result for prostate cancer was not statistically significant. A previous metaanalysis showed no significant relationships between schizophrenia and breast and lung cancer prevalence; it also revealed that patients with schizophrenia have low incidence risk of colorectal and prostate cancer [25].

These paradoxical findings have directed our attention to the association between schizophrenia and cancer incidence versus mortality risk. A meta-analysis published in 2017 revealed that patients with schizophrenia have a slightly decreased risk of overall cancer incidence compared with the general population [25]. Another meta-analysis based on 16 cohort studies showed a high risk of cancer mortality in individuals with schizophrenia [12]. Zhuo et al. described that female schizophrenia 
faced a higher incidence of breast cancer than the general population in a meta-analysis [26], whereas Li et al. found a decreased incidence of breast cancer in patients with schizophrenia [25]. Therefore, the association between cancer incidence and mortality risk in patients with schizophrenia remains vague on account of several potential confounding factors, such as gender, ethnicity, genetic background, cancer site, antipsychotic medication use, and cancer care [27, 28].

Evidence supports the possible increased risk of breast cancer in women with schizophrenia due partly to the use of antipsychotic medications [29], some of which may cause hyperprolactinaemia, which, in turn, may contribute to mammary development and breast carcinogenesis in animal and cell experiments [30, 31]. Johnston et al. found that two hyperprolactinemiainducing antipsychotics, risperidone and pimozide, incite precancerous cells to progress to cancer by activating JAK-STAT5 signaling [31]. Patients with schizophrenia show decreased incidence of prostate cancer [25, 32], which is theoretically related to low testosterone levels suppressed by high prolactin levels on account of antipsychotic drug use [33]. A case-control study revealed that the reduced risk of prostate cancer among patients with schizophrenia is likely associated with long-term treatment of high-dose phenothiazines (primarily chlorpromazine) [34].

Considerable research evidence suggests that genetic factors have been advocated to explain the decreased risk of several types of solid tumors among patients with schizophrenia. P53 and adenomatous polyposis coli polymorphisms may be associated with increased schizophrenia susceptibility and reduced vulnerability to lung and colon cancer in schizophrenia respectively [35-37]. The interaction of tumor suppressor genes TXNIP and AF1q may also contribute to risk for schizophrenia [38]. Wang et al. found that the reduced incidence of prostate cancer in schizophrenia patients may be related to JAZF1 gene mutation [39]. Some of tumor related-genes may be risk factors for the incidence of schizophrenia, and in the meanwhile they may act as protective factors for the development of cancer.

The mortality of different cancers is influenced not only by cancer incidence but also by increased risk of suicide, unhealthy lifestyle, late-stage diagnosis, poor survival after diagnosis, inadequate cancer treatment (e.g., surgery, chemotherapy, radiotherapy, endocrine therapy, and palliative care) [40-42]. Mitchell et al. demonstrated that individuals with schizophrenia are at a high risk of metabolic syndrome (MetS), which is a significant influence upon mortality. Screening for MetS risk factors and taking effective intervention measures, such as exercise, dietary changes and antipsychotic medication management, should be considered [43].
Due to the higher mortality from smoking-related illnesses than the general population, patients with schizophrenia are encouraged to receive pharmacotherapy and behavioral treatments to give up smoking [44]. Moreover, disruptions in the diagnosis and treatment of breast cancer are noticeable for patients with schizophrenia and result in adverse outcomes, including cancer recurrence [45]. Poor diagnostic evaluation and belated stage-appropriate treatment in lung cancer care are common among patients with schizophrenia and lead to poor outcomes [46]. Considering the disparities existent in cancer screening, diagnosis, treatment, and end-of-life care, collaboration between oncologists, psychiatrists, nurses, and other members of the multidisciplinary team is needed to provide high-quality care for patients with schizophrenia.

\section{Advantages and limitations}

Meta-analysis is an important tool to combine the results of included studies that may otherwise be uncertain or imprecise in a single study. The current meta-analysis presents a number of advantages. First, the study population was substantial, which means it has high statistical power. Second, our quantitative assessment was based on cohort studies to better understand the association between schizophrenia and mortality risk of site-specific cancers. Third, no publication biases was detected, which indicates that the pooled results may be stable.

Some limitations must be noted in our meta-analysis. First, on account of the low prevalence of schizophrenia and low cancer mortality in patients with schizophrenia, we ignored imparities in the measures of mortality rate and then calculated pooled RRs, which may produce negligible but inevitable statistical errors [17]. Second, all of the data used for meta-analysis were based on observational studies, and differences in unadjusted covariates are a potential source of bias. Moreover, some of the unrecorded factors may make a difference to the relationship between schizophrenia and mortality risk of site-specific cancers. Third, some data on the mortality risk of the four different cancers surveyed in this metaanalysis were lacking and could not be extracted from the included studies, resulting in outcome selection bias. Finally, although we used a random-effects model to meta-analyze RRs and performed sensitivity analyses to explore uncertainties in the included studies, considerable heterogeneity was still observed in some of our pooled results. Moreover, no adequate baseline information or adjusted confounding factors were available in most of the studies. We therefore cannot carry out meta-regression analyses to further explore the source of heterogeneity in these works. 


\section{Conclusion}

Despite some limitations, our meta-analysis demonstrates that patients with schizophrenia have increased risk of mortality from four site-specific cancers, including breast, lung, and colon cancer. Our findings emphasize that clinicians need not only to be aware of the elevated risk of cancer mortality, but also to recognize the differences in site-specific cancer incidence and mortality between schizophrenia patients and the general population. It seems imperative to address the disparities in cancer care and improve survival in people with schizophrenia after a diagnosis of cancer. Multidisciplinary assessment of medical and behavioral conditions is needed. The panel should promote healthy lifestyle intervention and offer individualized psychiatric treatment and anticancer therapy during the whole course of disease.

More research is needed to conduct the site-specific cancer risk assessment in people with schizophrenia. It is preferred to evaluate both incidence and mortality risk in a prospective cohort. To identify a more robust association between site-specific cancer mortality and schizophrenia, further studies need to adequately adjust for confounding factors, such as gender, genetic background, lifestyle, antipsychotic medication use, and cancer care. These cancers could be affected by the hormonally related or metabolic side effects of antipsychotic drugs should be given more attention.

\section{Supplementary information}

Supplementary information accompanies this paper at https://doi.org/10. 1186/s12888-019-2332-z.

Additional file 1: Figure S1. Metatrim test of studies included in metaanalysis of breast, lung and prostate cancer. Figure S2. Metaninf test of studies included in meta-analysis of breast, lung and prostate cancer.

\section{Abbreviations \\ Ap: All patients with schizophrenia; Cls: Confidence intervals; DSM: Diagnostic and statistical manual of mental disorders; Fp: Female patients with schizophrenia; HRs: Hazard ratios; I2: I-squared; ICD: International Classification of Diseases; MetS: Metabolic syndrome; Mp: Male patients with schizophrenia; N. of Subjects: The number of schizophrenia patients; NOS: Newcastle-Ottawa Quality Assessment Scale; NR: Non reported; NS: No significance; PRISMA: Preferred Reporting Items for Systematic Reviews and Meta-Analyses; RRs: Relative risks; SMRs: Standard mortality ratios; $x^{2}$ : chi-squared}

\section{Acknowledgements}

I would like to appreciate all people above for their contribution to this research.

\section{Authors' contributions}

LWN and YSZ conceived and designed the research. LWN, JLT, XYY, NY and RHW contributed to data collection, analysis and interpretation of data. LWN and YML performed the meta-analysis and drafted the manuscript. JW and $J H X$ helped in revising the manuscript. YSZ had primary responsibility for final content. All authors read and approved the final manuscript.

\section{Funding}

The current study was supported by grants from the second affiliated hospital of Soochow university pre-research project (SDFEYGJ1609), the second affiliated hospital of Soochow university clinical discipline group project funding (XKQ 2015008) and the project from national key laboratory of radiation medicine(GZK1201820). These three funding bodies contributed equally to the design of the manuscript, data collection, analysis,

interpretation of data and writing.

\section{Availability of data and materials}

All data generated or analysed during this study are included in this published article and its supplementary information files.

\section{Ethics approval and consent to participate}

Not applicable.

\section{Consent for publication}

Not applicable.

\section{Competing interests}

The authors declare that they have no competing interests.

Received: 7 July 2019 Accepted: 18 October 2019

Published online: 28 October 2019

\section{References}

1. Insel TR. Rethinking schizophrenia. Nature. 2010;468(7321):187-93.

2. Cohen ME, Dembling B, Schorling JB. The association between schizophrenia and cancer: a population-based mortality study. Schizophr Res. 2002;57(2):139-46.

3. Os JV, Kapur S. Schizophrenia. Lancet. 2009;374(9690):635-45.

4. Laursen TM, Nordentoft M, Mortensen PB. Excess early mortality in schizophrenia. Annu Rev Clin Psychol. 2014;10(10):425-48.

5. Musuuza JS, Sherman ME, Knudsen KJ, Sweeney HA, Tyler CV, Koroukian SM. Analyzing EXCESS mortality from cancer among individuals with mental illness. Cancer. 2013;119(13):2469-76.

6. Mortensen PB, Juel K. Mortality and causes of death in first admitted schizophrenic patients. Br J Psychiatry. 1993;163:183-9.

7. Saku M, Tokudome S, Ikeda M, Kono S, Makimoto K, Uchimura H, Mukai A, Yoshimura T. Mortality in psychiatric patients, with a specific focus on cancer mortality associated with schizophrenia. Int J Epidemiol. 1995;24(2): 366-72.

8. Perini G, Grigoletti L, Hanife B, Biggeri A, Tansella M, Amaddeo F. Cancer mortality among psychiatric patients treated in a community-based system of care: a 25-year case register study. Soc Psychiatry Psychiatr Epidemiol. 2014;49(5):693-701.

9. Tran E, Rouillon F, Loze JY, Casadebaig F, Philippe A, Vitry F, Limosin F. Cancer mortality in patients with schizophrenia: an 11-year prospective cohort study. Cancer. 2009:115(15):3555-62.

10. Olfson M, Gerhard T, Huang C, Crystal S, Stroup TS. Premature mortality among adults with schizophrenia in the United States. JAMA psychiatry. 2015;72(12):1172-81.

11. Kisely S, Crowe E, Lawrence D. Cancer-related mortality in people with mental illness. JAMA psychiatry. 2013;70(2):209-17.

12. Zhuo C, Tao R, Jiang R, Lin X, Shao M. Cancer mortality in patients with schizophrenia: systematic review and meta-analysis. Br J Psychiatry J Ment Sci. 2017;211(1):7-13.

13. Stroup DF, Berlin JA, Morton SC, Olkin I, Williamson GD, Rennie D, Moher D, Becker BJ, Sipe TA, Thacker SB. Meta-analysis of observational studies in epidemiology: a proposal for reporting. Meta-analysis of observational studies in epidemiology (MOOSE) group. JAMA. 2000;283(15):2008-12.

14. Higgins J, Green S. Cochrane Handbook for Systematic Reviews of Interventions Version 5.1.0. The Cochrane Collaboration; 2011. http:// handbook-5-1.cochrane.org.

15. Moher D, Liberati A, Tetzlaff J, Altman DG. Preferred reporting items for systematic reviews and meta-analyses: the PRISMA statement. BMJ. 2009; $339: \mathrm{b} 2535$.

16. Stang A. Critical evaluation of the Newcastle-Ottawa scale for the assessment of the quality of nonrandomized studies in meta-analyses. Eur J Epidemiol. 2010;25(9):603-5.

17. Greenland S. Quantitative methods in the review of epidemiologic literature. Epidemiol Rev. 1987;9(1):1-30.

18. Altman DG, Bland JM. How to obtain the confidence interval from a P value. BMJ. 2011;343(7825):681. 
19. Rosner B. Fundamentals of biostatistics. 7th ed. Duxbury: Thomson Learning; 2000.

20. Melsen WG, Bootsma MC, Rovers MM, Bonten MJ. The effects of clinical and statistical heterogeneity on the predictive values of results from metaanalyses. Clin Microbiol Infect. 2014;20(2):123-9.

21. Egger M, Davey Smith G, Schneider M, Minder C. Bias in meta-analysis detected by a simple, graphical test. BMJ. 1997;316(7129):469-71.

22. Brown S, Kim M, Mitchell C, Inskip H. Twenty-five year mortality of a community cohort with schizophrenia. Br J Psychiatry. 2010;196(2):116-21.

23. Kredentser MS, Martens PJ, Chochinov HM, Prior HJ. Cause and rate of death in people with schizophrenia across the lifespan: a population-based study in Manitoba, Canada. J Clin Psychiatry. 2014;75(2):154-61.

24. Crump C, Winkleby MA, Sundquist K, Sundquist J. Comorbidities and mortality in persons with schizophrenia: a Swedish national cohort study. Am J Psychiatry. 2013;170(3):324-33.

25. Li H, Li J, Yu X, Zheng H, Sun X, Lu Y, Zhang Y, Li C, Bi X. The incidence rate of cancer in patients with schizophrenia: A meta-analysis of cohort studies. Schizophrenia Res. 2018;195:519-28.

26. Zhuo C, Triplett PT. Association of Schizophrenia With the Risk of Breast Cancer Incidence: A Meta-analysis. Jama Psych. 2018;75(4):363-9.

27. Hodgson R, Wildgust HJ, Bushe CJ. Cancer and schizophrenia: is there a paradox? J Psychopharmacol. 2010;24(4 Suppl):51-60.

28. Bushe CJ, Taylor M, Haukka J. Review: mortality in schizophrenia: a measurable clinical endpoint. J Psychopharmacol. 2010;24(4 Suppl):17-25.

29. Wu Chou Al, Wang YC, Lin CL, Kao CH. Female schizophrenia patients and risk of breast cancer: A population-based cohort study. Schizophrenia Res. 2017;188:165-71.

30. De HM, Peuskens J, Sabbe T, Mitchell AJ, Stubbs B, Neven P, Wildiers H, Detraux J. Relationship between prolactin, breast cancer risk, and antipsychotics in patients with schizophrenia: a critical review. Acta Psychiatr Scand. 2016;133(1):5-22.

31. Johnston AN, Bu W, Hein S, Garcia S, Camacho L, Xue L, Qin L, Nagi C Hilsenbeck SG, Kapali J. Hyperprolactinemia-inducing antipsychotics increase breast cancer risk by activating JAK-STAT5 in precancerous lesions. Breast Cancer Res. 2018;20(1):42.

32. Raviv $G$, Laufer $M$, Baruch $Y$, Barak $Y$. Risk of prostate cancer in patients with schizophrenia. Compr Psychiatry. 2014;55(7):1639-42.

33. Torrey EF. Prostate cancer and schizophrenia. Urology. 2006;68(6):1280-3.

34. Mortensen PB. Neuroleptic medication and reduced risk of prostate cancer in schizophrenic patients. Acta Psychiatr Scand. 2010;85(5):390-3.

35. Cui DH, Jiang KD, Jiang SD, Xu YF, Yao H. The tumor suppressor adenomatous polyposis coli gene is associated with susceptibility to schizophrenia. Mol Psychiatry. 2005;10(7):669-77.

36. Park JK, Lee HJ, Kim JW, Park YH, Lee SS, Chang HI, Song JY, Yoon DJ, Bahn GH, Shin YH. Differences in p53 gene polymorphisms between Korean schizophrenia and lung cancer patients. Schizophr Res. 2004; 67(1):71-4.

37. Ozbey $U$, Yüce $H$, Namli M, Elkiran T. Investigation of differences in P53 gene polymorphisms between schizophrenia and lung Cancer patients in the Turkish population. Genet Res Int. 2010;2011(6):483851.

38. Su Y, Ding W, Xing M, Qi D, Li Z, Cui D. The interaction of TXNIP and AFq genes increases the susceptibility of schizophrenia. Mol Neurobiol. 2017; 54(6):1-7.

39. Wang KS, Zuo L, Owusu D, Pan Y, Luo X. Prostate Cancer Related JAZF1 Gene is Associated with Schizophrenia. J Schizophrenia Res. 2014;1(1).

40. Irwin KE, Henderson DC, Ba HPK. MPH WFPM: Cancer care for individuals with schizophrenia. Cancer. 2014;120(3):323-34

41. Chang CK, Hayes RD, Broadbent MTM, Hotopf M, Davies E, Møller H, Stewart R. A cohort study on mental disorders, stage of cancer at diagnosis and subsequent survival. BMJ Open. 2014;4(1):e004295.

42. Huang HK, Wang YW, Hsieh JG, Hsieh CJ. Disparity of end-of-life care in cancer patients with and without schizophrenia: a nationwide populationbased cohort study. Schizophr Res. 2018;195:434-40.

43. Mitchell AJ, Vancampfort D, Sweers K, van Winkel R, Yu W, De Hert M. Prevalence of metabolic syndrome and metabolic abnormalities in schizophrenia and related disorders--a systematic review and meta-analysis. Schizophr Bull. 2013;39(2):306-18.

44. Cather C, Pachas GN, Cieslak KM, Evins AE. Achieving smoking cessation in individuals with schizophrenia: special considerations. CNS drugs. 2017;31(6): $471-81$
45. Irwin KE, Park ER, Shin JA, Fields LE, Jacobs JM, Greer JA, Taylor JB, Taghian AG, Freudenreich O, Ryan DP. Predictors of disruptions in breast Cancer Care for Individuals with schizophrenia. Oncologist. 2017;22(11):1374-82.

46. Bergamo C, Sigel K, Mhango G, Kale M, Wisnivesky JP. Inequalities in lung cancer care of elderly patients with schizophrenia: an observational cohort study. Psychosom Med. 2014;76(3):215-20.

\section{Publisher's Note}

Springer Nature remains neutral with regard to jurisdictional claims in published maps and institutional affiliations.
Ready to submit your research? Choose BMC and benefit from:

- fast, convenient online submission

- thorough peer review by experienced researchers in your field

- rapid publication on acceptance

- support for research data, including large and complex data types

- gold Open Access which fosters wider collaboration and increased citations

- maximum visibility for your research: over $100 \mathrm{M}$ website views per year

At BMC, research is always in progress.

Learn more biomedcentral.com/submissions 